ARTICLE

Received 25 Sep 2014 | Accepted 10 Feb 2015 | Published 10 Mar 2015

DOI: 10.1057/palcomms.2015.5

OPEN

\title{
A Kantian-economic approach to altruism in the household
}

\author{
Mark D White
}

ABSTRACT Economists who study the family acknowledge the importance of altruism and resource allocation that occurs between family members, and have developed a number of novel approaches to modelling this behaviour. This article suggests a new method, based on the moral philosophy of Immanuel Kant, which will highlight several unique features of intrafamily altruism. After summarizing Kant's ethics and how it can be incorporated into the standard economic model of choice, I show how Kantian concepts of perfect and imperfect duty cast the standard models of intrafamily altruism and resource allocation in a new light. The inclusion of duty into the modelling explains how altruistic behaviour can continue when the affection has left a marriage, and blurs the lines between cooperative and non-cooperative models of resource allocation by highlighting the importance of binding commitment without external enforcement.

\footnotetext{
${ }^{1}$ Department of Philosophy, College of Staten Island, City University of New York, Staten Island, NY, USA (e-mail: profmdwhite@hotmail.com)
} 


\section{Introduction}

M

ainstream economics has long struggled to model ethical behaviour, including what is perhaps its simplest type, altruism. The standard assumption of homo economicus, an agent who maximizes his utility based on selfinterested preferences and exogenous resource constraints, serves well for much anonymous market activity of consumers, investors and business managers. It falls short, however, when dealing with behaviour outside this narrow band, especially interactions between persons who do not behave in a self-interested fashion towards each other.

Nowhere in economics is this of more concern than the economics of family, typified by interactions that are anything but anonymous and self-interested. Economists studying intrafamily altruism have modelled it using a variety of methods, ranging from "warm glow", multiple utilities and interdependent preferences, all of which have expanded the explanatory power of models in the field. However, most of the approaches used to model altruism in economics to this point have been rooted in the basic frameworks of preference satisfaction and utility maximization, both of which reflect the utilitarian thinking that lies at the heart of economic theory and prevent the consideration of principled behaviour that transcends preferences and utility.

In this article, I suggest an alternative way to model altruism in the family, in the form of a system of ethics that goes beyond the preference-satisfaction and welfare-maximization of mainstream economic models of choice to include concepts like commitment and obligation, which are of special relevance to family interactions. I will argue that the deontological ethics of Immanuel Kant offers a better framework for modelling the economic behaviour of agents within families, given the unique bonds between them. After a brief summary of Kantian ethics and how it can be integrated into the standard economic decision-making framework of constrained preference-satisfaction, I will survey the most popular models of intrafamily altruism and resource allocation, focusing on the nature of preferences, the use of interdependent utility functions and bargaining models used therein. Throughout, I show how a Kantian-economic model of choice casts these concepts in a new light and helps to expand the range of ethical motivations that economists can include in their models.

\section{Kantian ethics and the economic model of choice}

The best way to understand Kantian ethics is to begin with autonomy, the ability of persons to make moral decisions independent of both external authority and internal preferences and desires. ${ }^{1}$ In this sense, autonomy not only implies an independent and individual process of decision making but, more important, the possibility of counterpreferential choice: an agent can choose an action that corresponds with his or her moral code over the one that best satisfies his or her preferences. ${ }^{2}$ On the basis of their capacity for autonomous choice, Kant held that persons have dignity, an incalculable and incomparable worth that distinguishes them from mere things and implies that they are worthy of respect and consideration. It is this dignity, based on autonomy, that grounds the normative aspects of Kant's ethics.

Once we recognize the equal dignity of all persons, autonomy takes on moral content and becomes a responsibility as well as an ability. Kant argued that once people acknowledge the dignity of all persons, they must rationally act out of respect and consideration of them. To this end he developed the categorical imperative, a formalization of "the moral law", against which plans of action (or maxims) must be tested. If a maxim passes the categorical imperative test, it is permissible, but if it fails it is forbidden, resulting in a duty not to act on that maxim. For instance, a maxim of lying would be rejected by the categorical imperative-essentially because it fails to respect the dignity of others-and from this rejection we can derive a duty not to lie. More relevant for the purposes of this article, the categorical imperative would also reject a maxim of indifference to the suffering of others because it fails to show sufficient concern for others (as "ends in themselves"), which results in a duty of beneficence (or altruism). ${ }^{3}$

There are two types of duties that derive from the categorical imperative: perfect duties and imperfect duties. Perfect duties (or strict duties), such as the duty not to lie, admit of no exceptions in the interest of preferences or "inclinations". They are almost always negative in nature, and as such they act as constraints on choice and action. Imperfect duties (or wide duties), such as the duty of beneficence, are normally positive and do allow for latitude in their execution because of their generality. Rather than proscribing a particular action, they require the adoption of an attitude upon which the agent should act when he or she can. This allows for flexibility with respect to other duties as well as inclinations; for example, the duty of beneficence does not require ascetic sacrifice, but merely a sincere balancing of ones' interests with those of others (especially those close to you). In fact, at times Kant (1797: 451) could sound minimalist regarding the duty of beneficence: "when I say that I take an interest in this human being's well-being only out of my love for all human beings, the interest I take is as slight as an interest can be. I am only not indifferent with regard to him". ${ }^{4}$

For a person to be truly moral, however, it is not enough to act according to duty, but he or she must act out of respect for duty. An action is moral if it corresponds with duty, but a person is moral only if he or she is motivated by duty to perform that action. To use an example from the economics of the family, a "rotten kid" (Becker, 1981) behaves altruistically towards the head of the household and help to maximizing the family's wealth, which may be considered altruistic or ethical behaviour. However, the rotten kid's motivations are purely self-interested, so he or she is not a moral person. Even a person whose preferences take other persons' consumption or utility in account, such as the benevolently dictatorial head of household in Becker's model, is only moral if he or she distributes resources among the rest of the family out of duty rather than inclination.

This brief summary of Kantian ethics gives us enough to start augmenting the standard economic model of choice, or constrained preference satisfaction. ${ }^{5}$ According to this model, an agent starts with a preference ranking over available options; the basis of these preferences is typically not specified, although preferences are usually assumed to be fixed and to reflect simple self-interest (although neither assumption is necessary to the basic model). On the basis of this preference ranking, the agent chooses the highest option she can attain within her exogenous resource constraints (usually income, prices, and time). In economic terminology, her utility is formally understood to be an index of preference-satisfaction in which the more and higher preferences she can satisfy, the more utility she has; for this reason the economic model of choice is often characterized as utility maximization. ${ }^{6}$ If any of her constraints changes, she is likely to choose a different option to maximize her utility: an increase in income allows her to reach higher preferences, and a decrease in the price of a good she usually purchases allows her to buy more of it (and possibly other goods as well), both generating an increase in utility.

The challenge in incorporating Kantian ethics into the economic model of choice is determining how duty can be fit among preferences and constraints. Perhaps surprisingly, given the reputation of Kantian ethics as strict and unbending, the correspondence between the types of duty and the elements of the economic model is fairly straightforward. Perfect duties, which prohibit immoral actions, serve as constraints on the satisfaction 
of preferences alongside the normal resource constraints. At the same time, imperfect duties represent ethical attitudes and goals, the pursuit of which can sit alongside standard preferences (which are similar to what Kant called inclinations). With imperfect duties included among her preferences, and perfect duty acting with resource constraints to limit her choices, the agent chooses an action to maximize "utility" (understood now as an index of how much her broader preferences, including imperfect duties, are maximized), while not violating any strict moral duties. In this way, the agent follows the same decisionmaking process as usual, but her augmented preferences and constraints bring her choice roughly in line with Kantian ethics. This method of integration preserves the nature of perfect duties as prohibitions that are insensitive to preferences, cost or other circumstances, and also the substitutability Kant intended between imperfect duties and inclinations.

\section{Economic models of intrafamily altruism and Kantian beneficence}

Having presented the basic elements of Kantian ethics and the Kantian-economic model of choice, we now turn to the ways altruism has been modelled in the economics of the family, primarily in terms of intrafamily resource allocation. As I survey the main approaches in the literature, I will assess them in terms of the Kantian ideal of dutiful action (especially with respect to the duties of beneficence and promise-keeping), and will introduce more elements of the Kantian-economic model of choice, such as moral imperfection and weakness of will, which will highlight aspects of intrafamily altruism that are inexplicable with standard economic models.

Deferential and paternalistic preferences. Pollak (2003) provides a useful survey of the various ways that altruism has been modelled in the economics of the family, including that of Becker (1981). In this model, mentioned above, a head of the household has interdependent preferences, which include, to some degree, the utility of the other family members; these other members of the family may be purely self-interested or may have interdependent preferences themselves. Even if they are self-interested, according to Becker's "rotten kid theorem", they will behave altruistically towards the head of the household to maximize their own shares of the household resources. My concern here is less with the self-interested family members induced to altruistic behaviour-dismissed above as opportunistic-and more with the characterization of the head of household him- or herself.

The element of Pollak's critique that is of particular interest here is Becker's characterization of altruistic preferences. Pollak prefers to call them "deferential", as they are based on the family member's utility as determined by his or her own preferences, without any judgment of the part of the head of household regarding what the family member does to obtain that utility. Pollak (2003: 118) prefers to reserve the term "altruistic" for nondeferential preferences based on the particular goods consumed or activities enjoyed, so "a wife may, for example, want her husband to spend more time jogging because 'it's good for him', even though he would rather spend his time watching television". Such preferences could also be called "paternalistic", an uncontroversial term in political contexts that obviously takes on a different gendered connotation in discussions of the family; nonetheless, I will use it here because Kant's discussion of beneficence follows the same lines as political discussions of paternalism (White, 2013: 113-119).

There are several issues of importance to Kantian ethics in this debate. First, we have to consider the use the head of the household makes of his or her paternalistic preferences. Consider the example given above: it is one thing for a wife to prefer her husband jogs rather than watches television, and another entirely to force or manipulate him into doing so. ${ }^{8}$ Kant was very clear that when practicing beneficence, one has to respect the wishes of others rather than impose one's own preferences on them:

I cannot do good to anyone in accordance with $m y$ concepts of happiness (except to young children and the insane), thinking to benefit him by forcing a gift upon him; rather, I can benefit him only in accordance with his concepts of happiness. (Kant, 1797: 454)

Kant does make an exception for "young children", towards whom parents justifiably act paternalistically (or maternalistically), because they are immature and therefore not completely autonomous or responsible for their own actions. ${ }^{9}$ The quotation above presumably applies to mature adults, and would seem to favour Becker's version of altruistic preferences over that of Pollak.

But might the close relationship between partners relax this restriction somewhat? It may be inappropriate for the bakery clerk to refuse to sell me cakes because he thinks I should lose weight, but surely my friend or partner may try to stop me for the same reason, perhaps even knocking the sweet treat out of my hands! This conundrum gets to a conflict deep in Kantian ethics between respect and care: respect is owed to all persons equally, but care may be expressed to a greater degree to those closer to you, such as friends and family. ${ }^{10}$ So might care, in the case of family members, overwhelm respect, even with adults?

While Kant's discussion of marriage focused primarily on sex and property (Kant, 1797: 277-280), his discussion of friendship is far richer, and perhaps more relevant to modern marriages than it was in Kant's day. While often caricatured as a cold and formalistic moralist, Kant is one of the few early philosophers (together with Aristotle) to emphasize friendship, referring to it in the beginning of his discussion as "the union of two persons through equal mutual love and respect", which must be brought "into that equal balance required for friendship" (Kant, 1797: 469-470).${ }^{11}$ He wrote eloquently about the conflict between love and respect in friendship: "if the principle of love bids friends to draw closer, the principle of respect requires them to stay at a proper distance from each other" (Kant, 1797: 470). This conflict between the two attitudes essential to his system was of great concern for Kant, but he did not offer a definitive answer in favour of one or the other, choosing instead to reinforce the importance of both (and leaving it to each person's judgment to sort them out in any given situation). But it is reasonable to conclude that respect must never be sacrificed completely for the sake of care, and partners must be wary of overstepping boundaries when acting on non-deferential or paternalistic preferences.

If we assume altruistic preferences in Becker's sense (or deferential preferences in Pollak's terms), then we seem "safe" on Kantian grounds as well, concerning ourselves with others' happiness rather than their choices or behaviour. But does this make those with altruistic preferences moral as persons? As we saw before, that depends on why other people's happiness is included among preferences: if it is out of respect for the duty of beneficence, then the person is moral, but if it is based on natural feelings or sentiments of care, then the person is not necessarily moral for acting out of that interest.

Here is Kant's most infamous passage on this topic:

There are many persons who are so sympathetically constituted that, without any further motive of vanity or 
self-interest, they find an inner pleasure in spreading joy around them. ... In such a case an action of this kind, however dutiful and amiable it may be, has nevertheless no true moral worth. (Kant, 1785: 398)

This would argue against economic models of ethical behaviour based on getting a "warm glow" (such as Andreoni, 1990). It has also led to much criticism of Kant among philosophers, especially virtue ethicists (such as Stocker, 1976) who argue that helping a loved one precisely because he or she is a loved one is the more honourable motivation (see, however, Baron, 1984 for a defence of Kant on this issue). In later writings, Kant (1797: 456-457) argued that there is a duty to cultivate feelings of sympathy, even if only to reinforce the associated duties. Nonetheless, he continued to stress the primacy of duty: sentiments may come and go, after all, but the dictates of one's reason ought never to change.

Moral imperfection and interdependent utility functions. If interdependent preferences represent imperfect duty already, what can a Kantian approach add to such models? To answer this, I will introduce the concept of moral imperfection, which will enable us to examine ethical behaviour in situations of weakness of will and declining affections. To simplify matters, we will now dismiss children (off to bed!) and introduce the modern ideal of egalitarian marriage, putting aside the hierarchical element of Becker's altruistic model and assuming instead that partners each maximize interdependent utility functions (Bernheim and Stark, 1988).

Although Kant's ethics are often characterized as demanding, in actuality he was very realistic concerning human weakness in the face of temptation. Although the ability to make autonomous choices is present in every person, any one person's capacity for this is limited by his or her strength or resolve (what Kant termed "virtue"). No one has perfect resolve, and some have more than others, but every person should cultivate strength or resolve to follow the moral law in the face of temptation, because we are at the same time physical beings and rational beings. According to Kant, the way to acquire strength "is to enhance the moral incentive (the thought of the law), both by contemplating the dignity of the pure rational law in us and by practicing virtue" (Kant, 1797: 397), and this effort must be continuous, for "if it is not rising, [strength] is unavoidably sinking" (Kant, 1797: 409).

Strength (or weakness) of will can be included in the Kantianeconomic model of choice by assuming two objective functions that a person may maximize, representing two "paths" that he or she may follow (similar to the model in Steedman and Krause, 1986). One is characterized by perfect Kantian morality as described in the previous section, incorporating perfect and imperfect duties among standard constraints and preferences, and the other is the same path but without duties (while allowing other-regarding preferences based on inclination). The path that the agent follows in any given situation is modeled as a matter of "luck" based on his or her strength of will; if the agent had perfect self-control and could simply determine his or her path, we assume he or she would follow the moral path invariably. Therefore, a simple probability function is applied to the two objective functions, by which the stronger a person's resolve, the more likely he or she is to follow the path of morality in any given choice situation (White, 2011, Chapter 2).

We now apply this model to altruism between partners. For the time being, we will make the limiting assumption that they have no sympathetic preferences towards each other, and any altruism or beneficence between them arises solely out of duty. The moral path would be characterized as above (with perfect and imperfect duties), while the amoral path (at least in Kantian terms) would be the standard, narrowly self-interested utility function of neoclassical economics. Such a person will behave altruistically towards his or her spouse-sharing resources, giving gifts, helping with household tasks-according to his or her strength of will alone. These actions do not come naturally to this person out of preference or inclination, but rather he or she has to try to be nice -and when strength fails, the relationship suffers, as there are no sympathetic preferences to back them up.

Despite some descriptive validity of this characterization in many cases, we also want to focus on more affectionate marriages, in which the partners are naturally sympathetic to each other and would behave altruistically even in the absence of duty. In such relationships, duty and inclination would reinforce each other, overdetermining their altruistic behaviour, with the result that a person may behave kindly towards his or her spouse regardless of strength of will. In this case, the "temptation" is no temptation at all; the spouses are not tempted to lie or cheat, but simply to be kind by nature! But while their actions are good and kind, how can they know they are moral if their inclinations align with duty? This is a case of mixed motivations, of which Kant was very aware; because we can never know our true motivations regarding any action, he simply urged us to try to ensure that duty was a part of the motivation behind our moral actions, even if it is not the entire reason for them (Sullivan, 1994: 143-147).

But rather than making the duty-based model irrelevant, this is where Kant's insights regarding moral motivation become essential. In his critique of sentimentalism, Kant warns that sympathetic preferences waver or fade, but the essential pull of duty remains constant, and the moral person will always follow duties of beneficence regardless of the strength of any corresponding preference. Nearly every married person goes through periods of time in which he or she does not want to be kind to the other spouse for whatever reason, trivial or serious, transitory or persistent. During such periods, the natural sentiments of altruism disappear but, ideally, duty remains. The person who usually prepares dinner for the other spouse may continue to do it out of duty even when any inclination to do so suddenly disappears, replaced by an impulse to say "cook it yourself!" More important, if the affection between spouses fades significantly, or for longer periods of time, then duty has to pull more of the weight to inspire beneficence. At these times, low strength and resolve will reveal themselves in failures to maintain such behaviour-and may threaten to exacerbate any issues that led to the declining affections.

Standard interdependent utility functions used in the literature can be used to represent declining affections as well, by reducing the one person's coefficient on the other person's utility. But this cannot explain how or why partners with declining affections may still behave kindly to each other. The Kantian-economic model of choice can, however, because it incorporates ethical motivation that leads to counterpreferential choice, choice that reflects moral principle and duty over the satisfaction of preference. It is moral principle that helps us to do the right thing when we do not want to, including being nice and helpful to a spouse when we would much rather they suffer our wrath. And it is this dutiful beneficence that helps to smooth out rough patches in a marriage until the partners feel affectionate sentiments for each other once again (or, if this does not happen, the marriage is better dissolved).

Bargaining models and Kantian commitment. Having focused on imperfect duties of beneficence in the previous section, we shall now turn to perfect duties, particularly those concerning promise-keeping, which play an important role in bargaining 
models of intrafamily resource allocation (Manser and Brown, 1980; McElroy and Horney, 1981; Lundberg and Pollak, 1993). Such models are not primarily models of altruism, even though the agents in them may (in equilibrium) behave beneficently towards their partners and may even have interdependent utility functions. ${ }^{12}$ Instead, they focus on the relative bargaining power of the partners and the threat point against which they bargain, using a Nash bargaining equilibrium within a cooperative gametheoretic setting. It is this setting that requires the assumption of a certain degree of "caring" between the partners: "Since the marriage decision involves a degree of cooperation that may be absent in other types of bargains, a cooperative game approach is not an inappropriate one" (Manser and Brown, 1980: 36). As Lundberg and Pollak (1994: 133) recognize, "cooperative game theory begins by assuming that players can communicate freely and make binding, costlessly enforceable agreements".

Such agreements are easily understood as moral commitment in a framework of Kantian duty. ${ }^{13}$ Whether or not the partners include each other's utilities in their own objective functions, they implicitly agree to adhere to a Nash bargaining process, and therefore attain a Pareto efficient outcome corresponding to their relative opportunities in the absence of such agreement. Whereas Manser and Brown (1980) and McElroy and Horney (1981) assume this threat point is divorce or separation, Lundberg and Pollak (1993) assume it to be a non-cooperative Nash equilibrium within marriage, akin to the deteriorating marriage described above, in which neither sentiment nor duty is present to ensure beneficence among the spouses. In such a setting, Pareto efficiency is no longer guaranteed because of the possibility of suboptimal equilibria like Prisoners' Dilemma outcomes, especially with respect to contributions to household public goods such as childrearing (and participation in marriage counselling!).

As I showed elsewhere (White, 2009), an adherence to Kantian ethics by the players in a non-cooperative game does not guarantee that Prisoners' Dilemma outcomes will be avoided, as imperfect duties of beneficence do not require the type of potentially self-sacrificing behaviour involved in playing one's strictly dominated strategy. However, the meta-strategy of making binding promises can resolve Prisoners' Dilemma games efficiently because they allow the players to form binding agreements. Players with no regard for each other are not required to make such promises, especially if there is no guarantee the other players will make a similar promise (or hold to it). But partners in a relationship can make use of promises to avoid inefficient outcomes, even in the absence of any altruistic sentiments or in neglect of one's duties of beneficence, as long as a minimal level of trust exists among them. This would have the effect of transforming the non-cooperative game into a cooperative one, using moral commitment to enforce agreements (subject to moral imperfection and weakness of will, as before).

\section{Conclusion}

My modest goal in this article was to suggest how Kantian ethics can provide an alternative way to model altruism and resource allocation within the family. I also explained how the Kantian approach can enhance the explanatory and predictive power of these models, elaborating on motivational issues by accounting for moral imperfection and weakness of will. In this sense, the Kantian-economic interpretation of these topics maintains consistency with existing methodology while broadening its scope to include various types of motivation and the possibility of moral failure. Furthermore, while altruism was the most obvious topic within the economics of the family to which to apply Kantian ethics, all family interactions take place within a moral context of respect and concern, and can therefore benefit from a
Kantian-economic perspective. For instance, this approach can be applied fruitfully to topics such as intergenerational resource allocation, marital formation and dissolution, and fertility and childrearing, all of which involve economic issues of allocation and production within an explicitly affectionate and relational setting. Such a setting requires ethical concepts beyond those usually assumed in economic models-the impersonal and often antagonistic interaction of which can then be reserved for the study of relations with one's in-laws!

\section{Notes}

1 See Kant (1785) for his seminal presentation of the basic concepts of autonomy, dignity, the categorical imperative; see Sullivan (1994) for an approachable introduction.

2 For further discussion of counterpreferential choice, see Sen $(1977,1997)$

3 At this level of abstraction there is little need to explain the operation of the various formulae of the categorical imperative in detail; see Sullivan (1994) for an introduction and Paton (1947) for an extensive treatment.

4 For more on Kant's nuanced view of beneficence, see Kant (1797: 452-454).

5 For more on this model, see Hargreaves Heap et al. (1992).

6 Note that, in this sense, "utility" has little to do with happiness or pleasure, given that it only accounts for the satisfaction of preferences that are themselves void of psychological content; see Broome (1991) on many meanings of utility throughout the history of economics.

7 For more detail on the Kantian-economic model of choice, see White (2011), and for more on the role of judgment in balancing duties against each other and ordering imperfect duties among preferences, as well as the surprising flexibility of Kantian ethics it implies, see White (forthcoming).

8 This example recalls the "liberal paradox" from Sen (1970), as indicated by Pollak (2003: 118). Sen's liberal paradox points out the inconsistency between preference satisfaction and liberty when interdependent or "nosy" preferences are taken into account.

9 See also Kant (1797: 281-282) on parental obligations.

10 On this, see Kant (1797: 451-452), and compare to the discussion of Adam Smith and evolutionary biology in Bergstrom (1996: 1904-1910).

11 Compare this with his characterization of marriage as "the union of two persons of different sexes for lifelong possession of each other's sexual attributes” in Kant (1797: 227); see Denis (2001) for a revisionist approach to Kantian marriage and friendship that moderates the two and brings them closer together.

12 All three papers cited above mention this possibility but do not focus on it; see Manser and Brown (1980: 40-41), McElroy and Horney (1981: 335, 338) and Lundberg and Pollak (1993: 995).

13 See Sen (1977) for seminal work on commitment in economic models of choice.

\section{References}

Andreoni J (1990) Impure altruism and donations to public goods: A theory of warm-glow giving. Economic Journal; 100 (401): 464-477.

Baron M (1984) The alleged moral repugnance of acting from duty. Journal of Philosophy; 81 (4): 197-220.

Becker G S (1981) A Treatise on the Family. Harvard University Press: Cambridge, MA.

Bergstrom T C (1996) Economics in a family way. Journal of Economic Literature; 34 (4): 1903-1934.

Bernheim B D and Stark O (1988) Altruism within the family reconsidered: Do nice guys finish last? American Economic Review; 78 (5): 1034-1045.

Broome J (1991) Utility. Economics and Philosophy; 7 (1): 1-12.

Denis L (2001) From friendship to marriage: Revising Kant. Philosophy and Phenomenological Research; 63 (1): 1-28.

Hargreaves Heap S P, Hollis M, Lyons B, Sugden R and Weale A (1992) The Theory of Choice: A Critical Guide. Blackwell: Oxford.

Kant I (1785) Grounding for the Metaphysics of Morals, 1993 edn. Trans. Ellington J W. Hackett: Indianapolis, IN.

Kant I (1797) The Metaphysics of Morals, 1996 edn. Trans. Gregor M Cambridge University Press: Cambridge.

Lundberg S and Pollak R (1993) Separate spheres bargaining and the marriage market. Journal of Political Economy; 101 (6): 988-1010.

Lundberg S and Pollak R (1994) Noncooperative bargaining models of marriage. American Economic Review; 84 (2): 132-137.

Manser M and Brown M (1980) Marriage and household decision-making: A bargaining analysis. International Economic Review; 21 (1): 31-44.

McElroy M and Horney M (1981) Nash-bargained household decisions: Towards a generalization of the theory of demand. International Economic Review; 22 (2): 333-349. 
Paton H J (1947) The Categorical Imperative. University of Pennsylvania Press: Philadelphia, PA.

Pollak R A (2003) Gary Becker's contributions to family and household economics. Review of Economics of the Household; 1 (1): 111-141.

Sen A K (1970) The impossibility of a Paretian liberal. Journal of Political Economy; 78 (1): 152-157.

Sen A K (1977) Rational fools: A critique of the behavioral foundations of economic theory. Philosophy and Public Affairs; 6 (4): 317-344.

Sen A K (1997) Maximization and the act of choice. Econometrica; 65 (4): 745-779.

Steedman I and Krause U (1986) Goethe's Faust, arrow's possibility theorem and the individual decision-taker. In: Elster J (ed) The Multiple Self. Cambridge University Press: Cambridge, UK, pp 191-231.

Stocker M (1976) The schizophrenia of modern ethical theories. Journal of Philosophy; 73 (14): 453-466.

Sullivan R J (1994) An Introduction to Kant's Ethics. Cambridge University Press: Cambridge.

White M D (2009) Kantian ethics and the prisoners' dilemma. Eastern Economic Journal; 35 (2): 137-143.

White M D (2011) Kantian Ethics and Economics: Autonomy, Dignity, and Character. Stanford University Press: Stanford, CA.

White M D (2013) The Manipulation of Choice: Ethics and Libertarian Paternalism. Palgrave Macmillan: New York.
White M D (forthcoming) Judgment: Balancing principle and policy. Review of Social Economy; 73, in press.

\section{Additional Information}

Competing interests: The author declares no competing financial interests.

Reprints and permission information is available at http://www.palgrave-journals.com/ pal/authors/rights_and_permissions.html

How to cite this article: Mark D White (2015) A Kantian-economic approach to altruism in the household. Palgrave Communications 1:15005 doi: 10.1057/ palcomms.2015.1.

\section{(c) (i)}

This work is licensed under a Creative Commons Attribution 3.0 International License. The images or other third party material in this article are included in the article's Creative Commons license, unless indicated otherwise in the credit line; if the material is not included under the Creative Commons license, users will need to obtain permission from the license holder to reproduce the material To view a copy of this license, visit http://creativecommons.org/licenses/by/3.0/ 